\title{
REVISTAMARACANAN
}

Artigo

\section{Rendas e Gravatas: moda, identidade e gênero na Imprensa Ilustrada carioca, 1900-1914}

\author{
Laces and Ties: fashion, identity and gender in the Carioca illustrated press, \\ 1900-1914
}

Cláudia Maria de Silva de Oliveira* Universidade Federal do Rio de Janeiro, Brasil

Recebido: 13 ago. 2018.

Aprovado: 16 out. 2018.

\footnotetext{
* Professora Adjunta do Departamento de História da Arte e membro do quadro permanente do Programa de Pós-graduação em Artes Visuais da Escola de Belas Artes da Universidade Federal do Rio de Janeiro (UFRJ). Possui doutorado em História Social pela UFRJ e University of London; mestrado em História Social da Cultura pela Pontifícia Universidade Católica do Rio de Janeiro; e, graduação em História pela mesma instituição. Coordenadora do Grupo de Pesquisa do CNPq "Arte, Gênero e Cultura Visual". (olive.clau@gmail.com)

CV Lattes: http://lattes.cnpq.br/4485553418923188.
} 


\title{
Resumo
}

Este texto analisa o modo pelo qual certo estilo feminino de comportamento, associado a formas de vestir adotadas no Rio de Janeiro entre 1900-1914, numa subcultura feminina de grupos de mulheres que entravam no mercado de trabalho ou estavam em vias de profissionalização, era representado em imagens de imprensa cujos autores eram, na maioria, homens. Partimos da hipótese de que o jogo de exposição e representação das mulheres desses grupos, vistas como divergentes da cultura hegemônica burguesa por seu comportamento e vestuário, revelou um dispositivo criativo que subvertia os marcadores de gênero, por meio da manipulação de alguns sinais diacríticos - como roupas, ornamentos e performances públicas - que, aos olhos dos homens da imprensa, expressavam uma identidade feminina nova e híbrida, na qual feminino e masculino pareciam estar justapostos. Nesse jogo, o comportamento e as roupas daqueles grupos de mulheres são metáforas de uma individualidade feminina divergente, bem como dispositivos disruptivos da imagem da mulher frívola e domesticada, própria à época.

Palavras-chave: Rio de Janeiro. Imprensa. Vestuário. Gênero. Subcultura feminina.

\begin{abstract}
This text analyzes the way in which a certain feminine behavior associated with a certain dress style, which is progressively adopted by a female subculture, composed of groups of women entering the labor market or in the process of professionalization, in Rio de Janeiro, from 1900 to 1914, was represented in images by journalists, mostly men. Our hypothesis is that the exposition and representation of these groups of women, seen as divergent from the bourgeois hegemonic culture by their behavior and clothing, revealed a creative device that subverted the gender markers through the manipulation of some diacritical signs, such as clothes, ornaments and public performances, which in the eyes of the male press professionals expressed a new hybrid female identity, where the feminine and the masculine seemed to be juxtaposed. The behavior and the clothes of these groups of women are metaphors of a divergent female individuality, as well as a disruptive device of the image of women as frivolous and domesticated beings, proper to the time.
\end{abstract}

Keywords: Rio de Janeiro. Press. Fashion. Gender. Female Sub-Culture. 


\section{Introdução}

Este artigo propõe uma reflexão sobre o surgimento de novos comportamentos femininos associados a novos estilos de vestir que, em conjunto, criaram uma identidade feminina moderna, sintonizada com as transformações impostas pela Modernidade. As novas identidades femininas, no Brasil como, de resto, no Ocidente em geral, despertaram a ira e o desconforto masculinos - expostos na produção dos profissionais de imprensa, a maioria homens. Com base em fontes visuais encontradas em revistas ilustradas cariocas do começo do século $\mathrm{XX}$, momento marcado por transformações urbanas, pelo feminismo e pelo surgimento da própria imprensa ilustrada por fotografias, analisaremos o modo como aqueles profissionais representaram a relação entre o vestuário e o comportamento das mulheres que buscavam se inserir no mercado de trabalho. As revistas consultadas fazem parte da coleção da Biblioteca Nacional.

Nas representações visuais que as revistas fizeram desses novos grupos de mulheres, a aparência e a moda femininas tornaram-se dispositivos caraterizadores de uma mulher que recusava a domesticidade do lar, e, por isso mesmo, era vista como exaltada, transgressora, desobediente às instituições e infratora da doutrina social que separava as esferas por gênero, classe e, no caso do Brasil, também por raça. Reafirmavam-se, assim, os papéis insubmissos de vários grupos sociais, com as mulheres constituindo um desses grupos.

A partir de 1900, a mulher carioca que buscava educação e profissionalização, ao portar chapéu, gravata ou colete fazia dessas peças símbolos não apenas de glamour e sucesso, mas também de emancipação. Assim, o novo estilo de vestir feminino apresentado na imprensa carioca, se transformava em arma na batalha das aparências e, por consequência, em instrumento utilizado pelos cronistas homens das revistas ilustradas cariocas contra a luta feminina por direitos sociais e liberdade de ação. As balizas cronológicas são demarcadas pelo início da circulação de revistas ilustradas no Rio de Janeiro (O Malho, 1902; Fon-Fon!, 1907; Careta, 1908) e pelo fim da Belle Époque. ${ }^{1}$ Após 1914 e, especialmente, com o término da I Grande Guerra, em 1918, as novas formas femininas de vestuário e comportamento se disseminam entre as mulheres de diferentes classes e grupos sociais.

\section{Mulheres insubordinadas}

O poeta e crítico de arte francês Charles Baudelaire, em seu famoso ensaio "O pintor da vida moderna", publicado no jornal Le Figaro, em 1864, descrevia a mulher como uma das

\footnotetext{
${ }^{1}$ NEEDEL, Jeffrey D. Belle Époque Tropical: sociedade e cultura de elite no Rio de Janeiro na virada do século. São Paulo: Companhia das Letras, 1993.
} 
belezas que despontavam com a Modernidade no Ocidente. Para ele, o encanto e a sedução exercidos pela mulher moderna provinham da relação intrínseca entre beleza e aparência, relação essa traduzida no "binômio mulher e traje". 2

Em Baudelaire, a experiência histórica do moderno se amalgama com a experiência estética do moderno. Essa mescla põe em foco a problemática do moderno, formulada inicialmente no âmbito da estética e da crítica de arte, com a moda como elemento de destaque no contexto. Para Baudelaire, somente a moda encarnava sua concepção de moderno, pela qual o presente não ganha sentido em oposição ao passado, mas no entrecruzamento entre o efêmero e o eterno. Somente a moda sintetizaria, simbolizaria e concretizaria à perfeição esses dois conceitos, e por essa razão Baudelaire elevou-a a elemento fundante da autoconsciência do moderno. ${ }^{3}$ A moda foi, portanto, tratada pelo autor francês como elemento-chave em sua reflexão sobre o belo moderno e as identidades modernas.

Outra noção importante para a reflexão desenvolvida neste artigo refere-se à relação entre identidade e roupa. As identidades se ligam intimamente ao vestuário porque as roupas são a realidade empírica dos corpos vestidos e, assim sendo, expressam e moldam a identidade, imbuindo-a de uma realidade diretamente material. As roupas ligam o corpo biológico ao ser social, e o público ao privado. ${ }^{4}$ Para Monneyron, o vestuário nos obriga a reconhecer que o corpo humano é mais que uma entidade biológica: é também um organismo da cultura e um artefato cultural. O vestuário constitui, assim, a fronteira entre o eu e o não eu. ${ }^{5}$

Na obra Da Psicologia da moda: um estudo sociológico, o sociólogo fin de siècle Georg Simmel identificou a moda como um dos elementos constitutivos da hierarquia social. De acordo com Simmel, a moda nasce nas classes abastadas e desce progressivamente para as classes mais baixas, baseando-se na competição social e num processo de imitação e diferenciação que reforça a hierarquia social. ${ }^{6} \mathrm{Em}$ outro trabalho, A Mulher e a Moda, Simmel chama atenção para o fato de que as mulheres aderem à moda com particular exuberância, dada a debilidade de sua posição na hierarquia social - posição de inferioridade a que sempre estiveram condenadas. Assim, "a moda seria a válvula donde irrompe a necessidade de as mulheres se distinguirem e realçarem a sua individualidade segundo uma maior ou menor medida, quando tal satisfação lhes é recusada nas outras áreas. ${ }^{77}$ Pois a existência da mulher como

pária social, declarado ou latente, desperta nela uma aversão contra tudo o que já está legalizado, firmemente estabelecido. [...] na contínua aspiração a modas

\footnotetext{
${ }^{2}$ BAUDELAIRE, Charles. As Flores do Mal. Edição bilíngue. Tradução, introdução e notas: Ivan Junqueira. Rio de Janeiro: Nova Fronteira, 1985, p. 54.

${ }^{3}$ WAIZBORG, Leopoldo. Georg Simmel sobre a moda - uma aula. IARA - Revista de Moda, Cultura e Arte, São Paulo, v. 1, n. 1, abr./ago. 2008.

${ }^{4}$ WILSON, Elizabeth. Enfeitada de Sonhos. São Paulo: Edições 70, 1985, p. 85.

${ }^{5}$ MONNEYRON, Fréderic. A Moda e seus Desafios: 50 questões fundamentais. São Paulo: Ed. Senac, 2007, p. 45.

${ }^{6}$ SOUZZA, Jessé; ÖELZE, Berthold. Simmel e a modernidade. Brasília: UnB, 1998, p. 161-170.

${ }^{7}$ Ibidem, p. 61.
} 
novas [...] habita uma forma estética da pulsão destruidora que se afigura própria de todas as existências párias, enquanto ainda não estão de todo escravizadas. ${ }^{8}$

A competição entre classes sociais é o motor da moda para Simmel, como também para Pierre Bourdieu, que afirmou em seu texto "O Costureiro e sua Grife" o papel da roupa como marcador de distinção de classe, mostrando como o vestuário é um aspecto do capital cultural, parte do modo como as elites estabelecem, mantêm e reproduzem suas posições de poder por meio do reforço da relação de dominação e subordinação de classes. ${ }^{9}$ Para o autor, as criações de moda funcionam como instrumentos de diferenciação, primeiro entre as frações de uma mesma classe e, em seguida, entre as próprias classes. ${ }^{10}$

Estudos mais recentes no campo da moda têm, porém, desafiado essa reflexão apoiada na competição entre classes sociais. A democratização da moda e a ascensão das subculturas e dos estilos de rua tornaram menos central a dinâmica das classes sociais. ${ }^{11}$ Outros aspectos da identidade são cada vez mais enfatizados na reflexão sobre a construção das modas. Dentre tais aspectos, o gênero tem se destacado como o mais significativo.

Teóricos contemporâneos como Entwistle e Williams apresentam a moda como elemento essencialmente relacionado ao gênero. Ao afirmarem que a roupa foi usada ao longo da história para esconder ou ressaltar a diferença sexual no seu sentido mais intrínsicamente biológico, fazem também do gênero um marcador de códigos de vestuário. Tais análises mostram como a moda ajuda a reproduzir o gênero como uma forma de estilo corporal, revelando assim a existência de uma interação complexa entre os corpos sexuais e as identidades de gênero e entendendo as ambivalências de gênero como centrais à moda. ${ }^{12}$

Por outro lado, as reflexões contemporâneas sobre gênero e moda têm sido produzidas pelo viés feminista. Para as feministas da segunda onda - a etapa do feminismo que surgiu na década de 1960 - a moda era uma importante forma de identidade de gênero que incorporava práticas destinadas a objetificar e limitar as mulheres, reforçando sua associação cultural com o narcisismo e a trivialidade. Mais recentemente, feministas influenciadas pelas análises pósmodernistas passaram a ter uma visão menos negativa da moda, reconhecendo a inescapabilidade das questões de estilo e formação cultural em relação ao corpo e à aparência. As novas pensadoras passaram a ver a moda como parte de uma cultura feminina, um campo de prazer e expressão que vai além da reprodução do patriarcado, do capitalismo e da dominação de classes, visto que a moda também define e redefine as fronteiras de gênero. ${ }^{13}$

\footnotetext{
${ }^{8}$ SOUZA, Jessé; ÖELZE, Berthold. Simmel e a. Op. cit., p. 55.

${ }^{9}$ BOURDIEU, Pierre. O costureiro e sua grife - contribuição para uma teoria da magia. In: $A$ produção da crença: contribuição para uma economia dos bens simbólicos. São Paulo: Zouk, 2002, p. 67.

${ }^{10}$ Ibidem, p. 75.

${ }^{11}$ CRANE, Diana. A Moda e seu Papel Social: classe, gênero e identidade das roupas. São Paulo: Ed. Senac, 2013.

${ }^{12}$ ENTWISTLE, Joanne. El cuerpo y la moda. Barcelona: Paidòs Ibérica, 2002; WILLIAMS, Caroline. A percepção de gênero através da moda. Tradução de Rachel Cordeiro. IARA - Revista de Moda, Cultura e Arte, São Paulo, v. 5, n. 1, maio 2012.

${ }^{13}$ EVANS, Caroline; THORNTON, Mina. Fashion, Representation, Femininity. Feminism Review, n. 38, 4866, Summer 1991.
} 
Historicamente, até o fim do Antigo Regime, no século XVIII, as diferenças sexuais no vestuário não eram tão fortemente assinaladas. As diferenças de gênero passam a ser profundamente marcadas pelas formas de vestir ao longo do século XIX, com a emergência da Modernidade. Os trajes tornam-se, na sociedade burguesa, um instrumento importante de diferenciação sexual, e a aparência da mulher burguesa transforma-se em uma produção artística. A roupa passa a fazer parte da personalidade da mulher; e torna-se elemento constitutivo do processo de mobilidade social, visto que adentra a economia matrimonial e o casamento era o único caminho para a segurança econômica da mulher à época.

O novo papel do vestuário se estendeu para além da aparência, misturando-se com a identidade. Era o início do Eu feminino visto como obra de arte. Assim, traje e adornos unidos à beleza e à amabilidade construíam o ideal de mulher na sociedade burguesa moderna no século XIX, despertando para o que o crítico de arte John Berger classificou como "a presença social da mulher". Para Berger, a "presença social da mulher" manifestava-se, na Modernidade, "através de seus gestos, voz, opinião, expressão, roupas, gosto, despertando no homem uma emanação física, uma aura", enquanto a "presença social do homem" se manifestava pelo seu poder. ${ }^{14}$

A emergência dos grandes centros urbanos modernos no Ocidente produziu, ao longo do século XIX, e, posteriormente, no começo do século XX, uma nova estética, estudada por Baudelaire e Simmel, como vimos. Novas formas de beleza associadas a novas formas de identidade, que combinavam a grandeza masculina ao fascínio e encanto femininos, eram apropriadas pela paisagem urbana que também se modificava. Mulheres de todas as classes sociais passaram a fazer das ruas um lugar de prazer, de exibição e de voyeurismo. A exibição dos indivíduos pelas ruas da cidade e o consumo de bens de luxo criaram uma estética da sedução. Esse novo universo urbano, tomado por uma massa anônima, tornava-se repleto de símbolos que serviam para subverter o anonimato: era importante distinguir-se socialmente e as roupas se apresentavam como chaves de leitura de comportamento e de personalidade. Os trajes se constituíam em símbolos poderosos na arte de dissimular e disfarçar.

A novidade da exposição da mulher no espaço público produzia uma poderosa troca de olhares entre homens e mulheres, levando à prática da "escofilia": experiência visual feminina que concentra ao mesmo tempo o prazer de olhar e o de ser admirada pelo olhar masculino. ${ }^{15}$ Essa experiência, segundo Berger, traduz a relação visual entre homens e mulheres na Modernidade e está carregada de uma relação de poder masculino, já que, nela, "os homens agem e as mulheres aparecem". ${ }^{16}$ Assim, na "escofilia" o olhar feminino é igual ao masculino, no sentido de que as mulheres se vêem através dos olhos dos homens. ${ }^{17}$ Mas a correspondência entre o ato visual masculino de julgar e a prática feminina de policiar-se confinava a mulher em um espaço de ação social limitado - de forma que, mesmo adentrando

\footnotetext{
${ }^{14}$ BERGER, John. Ways of Seeing. London: British Broadcasting Corporation; Penguin, 1972, p. $41 ; 46$.

${ }^{15}$ MULVEY, Laura. Visual and Other Pleasures: language, discourse, society. London: Palgrave; Macmillam, 2009, p. 98.

${ }^{16}$ Berger, John. Ways of Seeing. Op. cit., p. 65.

17 MULVEY Laura. Visual and Other... Op. cit., p. 64.
} 
o espaço público, as mulheres, em sua maioria, continuaram a viver sob a tutela masculina, aprisionadas à ideologia da domesticidade.

A prática da "escofilia" apresenta, porém, um duplo dinamismo, visto que, ao mesmo tempo em que tutela a mulher, também Ihe dá prazer. Além disso, as identidades (femininas ou masculinas) são multidimensionais, híbridas e em constante transformação. As teorias feministas pós-estruturalistas têm mostrado as maneiras pelas quais as identidades e subjetividades de gênero sempre foram socialmente construídas, rejeitando, assim, a categorização das mulheres como um grupo homogêneo, bem como a visão de que o feminino e a feminilidade sejam concepções unitárias. Em tais análises, as identidades não são fixas, estáticas e de natureza binária, mas são discursivamente negociadas e renegociadas. ${ }^{18}$

Assim, duas assertivas se aplicam ao contexto feminino na Modernidade: a primeira mostra que as mulheres se constituem em sujeitos; a segunda chama atenção para o fato de que a rua moderna - desde meados do século XIX até as primeiras décadas do século XX - não foi espaço exclusivo de mulheres burguesas das classes altas, que, envoltas em "festão e debrum", ${ }^{19}$ faziam do espaço público lugar de prazer e exibição. A rua moderna era também ocupada por mulheres da pequena e média burguesia, à procura de um lugar no mercado de trabalho. Para essas mulheres, a rua era, além de lugar de prazer e de exibição, um espaço de acesso ao exercício do trabalho - condição que, até aproximadamente a década de 1880, era reservada aos homens.

Muitas mulheres da pequena e média burguesia estavam engajadas na subcultura feminista: aspirando a uma redefinição do lugar e do papel da mulher na sociedade burguesa, buscavam acesso à educação, ao mercado de trabalho e à cidadania plena. Para os homens, essas mulheres que aspiravam adentrar o espaço público em busca de trabalho e realização profissional eram percebidas como marginais à ideologia masculina burguesa dominante, porque fugiam às regras de domesticidade estabelecidas em benefício dos homens. Ao redefinirem sua posição na hierarquia social, através da educação e do trabalho, tais mulheres passavam de objeto a sujeito, escapando, assim, da tutela masculina.

Nesse contexto, as roupas e a aparência da mulher, além de funcionarem como indicadores de status e distinção entre indivíduos e classes sociais, tornaram-se também elementos de regulação de condutas e hábitos. ${ }^{20}$ As mulheres que, desde a década de 1880 na Europa e nos Estados Unidos, começavam a ter acesso à educação e a adentrar o mercado de trabalho, eram vistas como marginais e ridicularizadas na imprensa, sobretudo pelo estilo de vestir contrário ao estilo burguês pautado na domesticidade. Esse estilo, classificado pela socióloga da moda Diana Crane como "alternativo" e "não convencional", ${ }^{21}$ consistia no uso de peças do guarda-roupa masculino, como gravata, chapéu, paletó, colete e camisa, misturadas

\footnotetext{
${ }^{18}$ BUTLER, Judith. Problemas de Gênero: feminismo e subversão da identidade. Rio de Janeiro: Civilização Brasileira, 2015, p. 25-26.

${ }^{19}$ BAUDELAIRE, Charles. As flores do mal. Op. cit., p. 361.

${ }^{20}$ ROCHE, Daniel. A Cultura das Aparências: uma história da indumentária (séculos XVII-XVIII). São Paulo: Ed. Senac, 1989, p. 22.

${ }^{21}$ CRANE, Diana. A Moda e seu... Op. cit., p. 197.
} 
a peças do guarda-roupa feminino. Foi adotado, principalmente, mas não de forma exclusiva, por mulheres jovens que almejavam independência. Eram estudantes, profissionais liberais, acadêmicas; e, também, professoras primárias, comerciárias, telefonistas, datilógrafas e trabalhadoras de escritório em geral. No início do século $\mathrm{XX}$, as grandes capitais do Ocidente estavam tomadas por mulheres que adotavam esse guarda-roupa, e seu número crescia à medida que aumentava o número de mulheres instruídas e profissionais.

A história da indumentária esportiva feminina mostra que itens do guarda-roupa masculino começaram a ser usados em meados do século XIX por damas das classes altas da Europa e dos Estados Unidos, para passeios a cavalo ou de bicicleta e em caminhadas e piqueniques. Posteriormente, essa indumentária feminina esportiva foi adotada fora do âmbito esportivo, por mulheres das classes médias e baixas que entravam no mercado de trabalho e ocupavam profissões até então consideradas masculinas. De modo que, seguindo as análises de Simmel e Bourdieu, entendemos que os trajes esportivos usados inicialmente pelas mulheres das classes altas se espalharam entre as mulheres de toda a hierarquia social, constituindo o coração do estilo alternativo que seria progressivamente adotado no cotidiano por mulheres das classes médias e trabalhadoras - a partir da segunda metade do século XIX na Europa e nos Estados Unidos, e no início do século XX no Brasil. O estilo era discreto, mas parecia masculinizar a figura feminina, porque os trajes aludiam à vestimenta do homem de negócios. Ao combinar o porte profissional masculino com as peças habituais do guarda-roupa feminino, o traje continha a sugestão de respeitabilidade e seriedade associadas ao trabalho não doméstico. Mas, ao embaralhar, através das roupas, os códigos fixos de gênero, o novo estilo de vestir parece ter despertado, especialmente nos homens, um desconforto com a mulher que parecia eliminar sua sexualidade e, com ela, seu gênero. De modo que dois tipos de vestir surgiam paralelamente entre as mulheres a partir de fins do XIX e das duas primeiras décadas do XX: o vestir-se para ter uma aparência profissional e o vestir-se para ser sexualmente atraente.

\section{Mulheres profissionais: o feminino imperfeito}

No Rio de Janeiro do início do século XX, um conjunto grande de mulheres passou a ocupar os novos espaços urbanos após as reformas capitaneadas pelo engenheiro Pereira Passos e pelo médico sanitarista Oswaldo Cruz, entre 1903 e 1906. A Avenida Central e seu entorno se converteram na meca para compras e exibição das aparências. Nessas áreas, a "escofilia" e o voyeurismo tornaram-se também instrumentos da economia visual e estavam diretamente relacionados ao universo da mulher e da moda. Em agosto de 1909, um cronista de Fon-Fon! descrevia as novas levas de senhoras e senhoritas que ele, como um flaneur baudelairiano, via deambular pelas calçadas da Avenida ou descer dos bonds ou circular pela 
Rua do Ouvidor, exibindo "saias farfalhantes, de seda ou rendada, finas essências [...] capitosos dessous, sapatos de verniz ou botas esguias de cano alto de cor havana".

Entre as mulheres e homens da elite carioca, o ideal feminino de beleza era la parisienne e não a mulher norte-americana, que despertava visões de rebeldia e liberdade. Nada de liberdade para as mulheres, muito menos de feminismo, visto por aqui como sinônimo não só de insubmissão, mas de demonstração da exaltação de um grupo de mulheres das classes médias e baixas, brancas pobres ou negras, que odiavam os homens e desejavam ocupar o espaço masculino no mercado de trabalho. Mas, por aqui também, algumas mulheres já frequentavam cursos superiores, outras começavam a trabalhar no comércio e em escritórios e uma parte delas, especialmente as professoras primárias, começava a engrossar as fileiras do movimento feminista que aqui reverberava desde a segunda metade do século XIX. ${ }^{22}$

Assim, no início do século $X X$ iniciam-se transformações importantes na hierarquia social, visto que os espaços sociais de gênero começam a se entrelaçar com o progressivo ingresso de mulheres das classes média e baixa no mercado de trabalho. Essas mudanças foram acompanhadas, de um lado, por uma ampla discussão em torno dos direitos da mulher, como a conquista de uma cidadania plena, capitaneada pelo grupo de mulheres feministas; e, de outro lado, por uma ampla cobertura da imprensa que, em textos e fotografias, associava as conquistas femininas - para o bem ou para o mal - ao que denominavam de "Feminismo no Brasil" ou "Nosso Feminismo".

Desde o século XIX, as imagens fotográficas propagavam estilos de comportamento feminino associados a estilos de vestir. No início do século $X X, 0$ amplo uso da fotografia nas revistas ilustradas criou um novo modo de olhar e de avaliar a beleza de uma mulher. Segundo a historiadora da moda Lou Taylor, a paixão pela fotografia em preto e branco é uma sensibilidade modernista. ${ }^{23} \mathrm{~A}$ imagem fotográfica capturava o sentido das roupas modernas e, com isso, influenciava as mulheres, que eram as principais consumidoras de moda e leitoras das revistas. A fotografia converteu-se na nova arte da representação do indivíduo em público, tornando-o mais consciente de sua aparência.

Pelos registros visuais encontrados nas revistas ilustradas que começavam a circular no Rio de Janeiro do início do século $\mathrm{XX}$, podemos perceber que um guarda-roupa alternativo ao da mulher burguesa começou a ser usado aqui especialmente pelas professoras primárias. Essa categoria de profissionais mulheres despertava uma visão paradoxal. De um lado, elas eram muito respeitadas por sua função de educadoras. Não raramente, apareciam nas colunas reservadas pelas revistas ilustradas à apresentação do grand monde carioca, como a "Nossos Instantâneos" de Fon-Fon!. Na fotografia publicada na edição de Fon-Fon! de julho de 1907 (Figura 1), vemos um grupo de professoras elegantemente vestidas. As mulheres parecem reproduzir na foto tirada na Avenida Central a mesma conduta que mantinham em sala de

\footnotetext{
${ }^{22}$ HAHNER, June E. A Mulher Brasileira e suas lutas sociais e políticas: 1850-1937. São Paulo: Brasiliense, 1988, p. 98.

${ }^{23}$ TAYLOR, Lou. Establishing Dress History. Manchester: Manchester University Press, 2004, p. 88.
} 
aula, descrita por Guacira Louro em sua reflexão sobre o comportamento das professoras em classe. Segundo a autora, a professora em sala conservava o rosto fechado, nenhum sorriso, nenhum afeto, nenhum contato corporal, nenhuma demonstração de sexualidade. A severidade era a prova de seu comportamento ilibado. ${ }^{24}$ Com base na imagem fotográfica, podemos inferir que a conduta das professoras no espaço público reproduzia o ambiente da sala de aula.

\section{Figura 1}

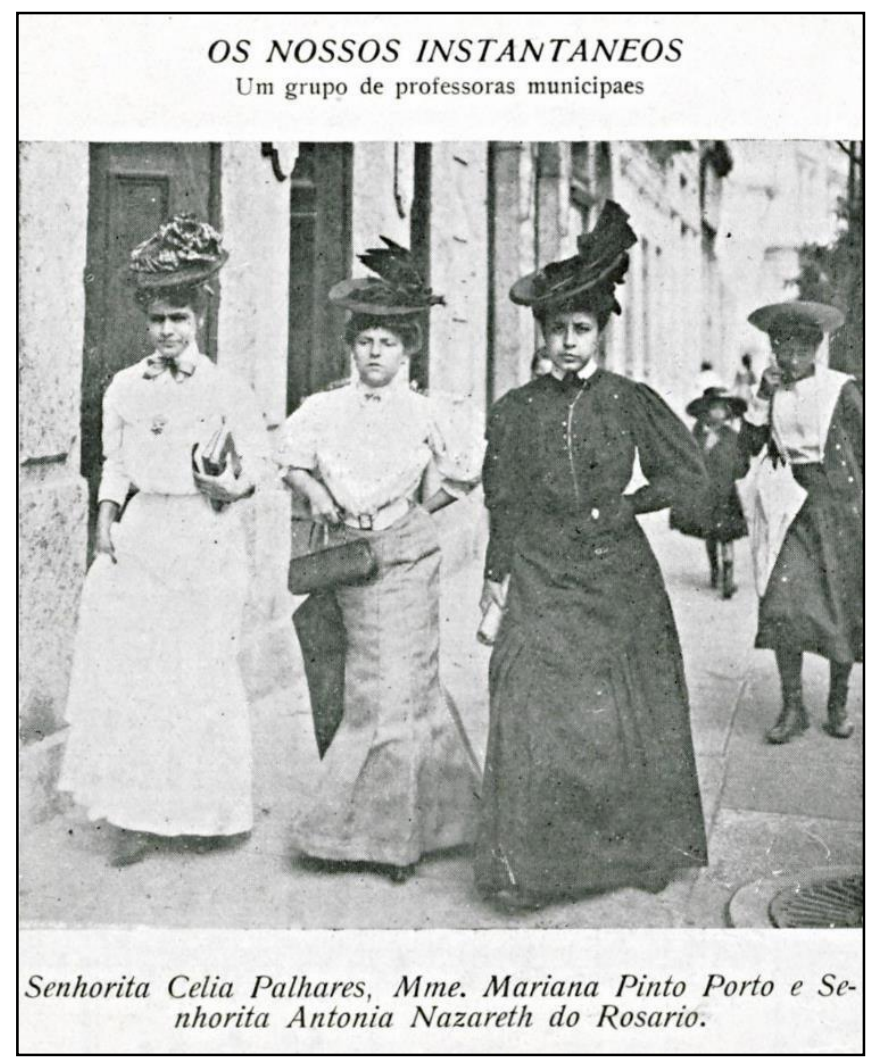

Fonte: Fon-Fon!, ano 1, n. 16, p. 16. Rio de Janeiro, 27 jul. 1907.

Seus trajes também, embora elegantes, eram compostos por itens evidenciadores de seriedade, como o uso de peças do guarda-roupa masculino misturadas às peças do guardaroupa feminino tradicional: saia acompanhada de blusa ou camisa com mangas largas, com punhos dobrados e abotoados; o colarinho alto e dobrado; o pescoço envolto em grandes lenços, foulards fechados com broche ou com gravata-borboleta; e a cintura, marcada pelo uso do cinto. A primeira jovem, à esquerda, carrega livros; e a do centro e a da direita seguram rolos de papel - mais elementos indicadores da mulher profissional. O uso de gravata, foulard, lenço no pescoço, punhos dobrados e cinto, associado aos livros e aos rolos de papel, era indicativo de mulher com acesso à educação e ao mercado de trabalho. Observamos, assim, que o traje das professoras se diferenciava da indumentária da mulher burguesa, porque

\footnotetext{
${ }^{24}$ LOURO, L. Guacira. Mulheres na sala de aula. In: DEL PRIORY, Mary; PINSKY, Carla B. (orgs.). História das Mulheres no Brasil. São Paulo: Contexto, 2011, p. 448.
} 
constituía a afirmação de uma feminilidade que invocava severidade e se apresentava de acordo com a função social daquela categoria de mulheres: as profissionais.

Mas, se de um lado vemos imagens de elegantes professoras primárias clicadas e apresentadas pelas revistas ilustradas em espaço reservado às elites, é preciso registrar que, de outro lado, um grande número de professoras primárias vivia em condições difíceis: recebiam parcos rendimentos - a metade dos auferidos pelos professores homens, o que as obrigava a viver frugalmente. Em "Jornal de uma feminista", uma crônica de 1909 publicada em 1933 no livro póstumo Almas complexas, a escritora Carmen Dolores delineia a imagem triste e patética de uma professora primária feminista. A personagem, que vive no limite de suas possibilidades financeiras, sente-se uma fracassada envolvida numa luta inglória. Sentada diante do espelho, associa sua imagem triste a seus trajes quase indigentes e até equipara sua aparência com a de um homem. Além de "magra, abatida e murcha", a pobre professora vestia "botinas gastas, chapéu usado e jaquette azul-marinho surrada, que o suor das longas caminhadas em dias de verão esbranquiçara às costas"; e, como um homem, "caminhava a passos dobrados consultando as horas". Assim, a descrição que a autora faz da professora feminista ressalta uma feminilidade que se opõe inteiramente ao ideal feminino burguês e, por isso, "ela só merecia do vulgo o escárnio". 25

O que tais representações visuais e textuais nos revelam sobre a mulher profissional em busca de emancipação? Na construção da nova identidade feminina, o comportamento e os trajes de cada grupo são marcadores de distinção entre classes e grupos sociais, como nos dizem Georg Simmel e Pierre Bourdieu; mas também indicam um novo estilo de comportamento social que foge à normas tidas como naturais à mulher. As mulheres brancas de elite encarnavam, nas imagens fotográficas, uma identidade feminina marcada pela domesticidade e pela tradição da separação dos papéis sexuais; e tinham como modelo a moda francesa e a parisienne. Já as mulheres da classe trabalhadora, da pequena burguesia e as feministas tinham sua feminilidade construída no desvio da ordem. A percepção do desvio era dada pelos novos comportamentos em público, associados a um estilo de vestir que relacionava pertencimento e comportamento social à indumentária. No caso das professoras, em que pese o fato de que muitas viviam modestamente, ainda assim o magistério deu a esse grupo de mulheres mais independência econômica e liberdade de circulação. Sobretudo, sua inserção no mundo do trabalho incentivou a progressiva entrada de outras mulheres em carreiras consideradas masculinas, como as profissões liberais - estas últimas, vedadas ao sexo feminino até aproximadamente a década de 1880.

A foto de jovens estudantes de Belas Artes (Figura 2), integrantes da turma de pintura de Eliseu Visconti na ENBA - Escola Nacional de Belas Artes -, publicada em 1910 na revista Fon-Fon!, mostra um grupo composto por três rapazes e quatro moças. Todos posam para a fotografia em posições e trejeitos irreverentes, exibindo pela linguagem corporal a maneira como iam contra as normas da sociedade e da boa educação. Parecem querer mostrar

${ }^{25}$ DOLORES, Carmen. Almas Complexas - Contos. Santa Catarina: Editora Mulheres, 2014, p. 89. 
para o fotógrafo que viviam a vida alegremente e à vontade, livres de convenções sociais. Da esquerda para a direita, vemos a estudante de pintura Isolina Machado usando uma gravata Ionga; a quarta jovem, Fedora Rego Monteiro, veste um jaquetão. Ambas usam o vestuário da jovem moderna: peças masculinas complementadas com itens da indumentária feminina, a qual é representada pela cintura apertada com cinto largo, cabelos longos arranjados em coques, blusa de mangas volumosas e saias delicadamente ajustadas. O paletó e a gravata, para aquelas jovens, naquele momento, eram símbolos de rebeldia e emancipação.

\section{Figura 2}

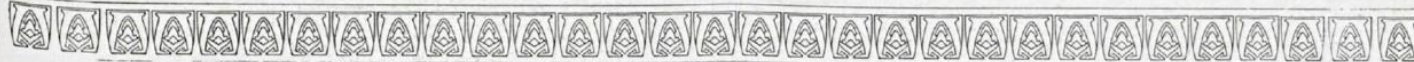

\section{Fon-Fon! na Academia de Bellas Artes}

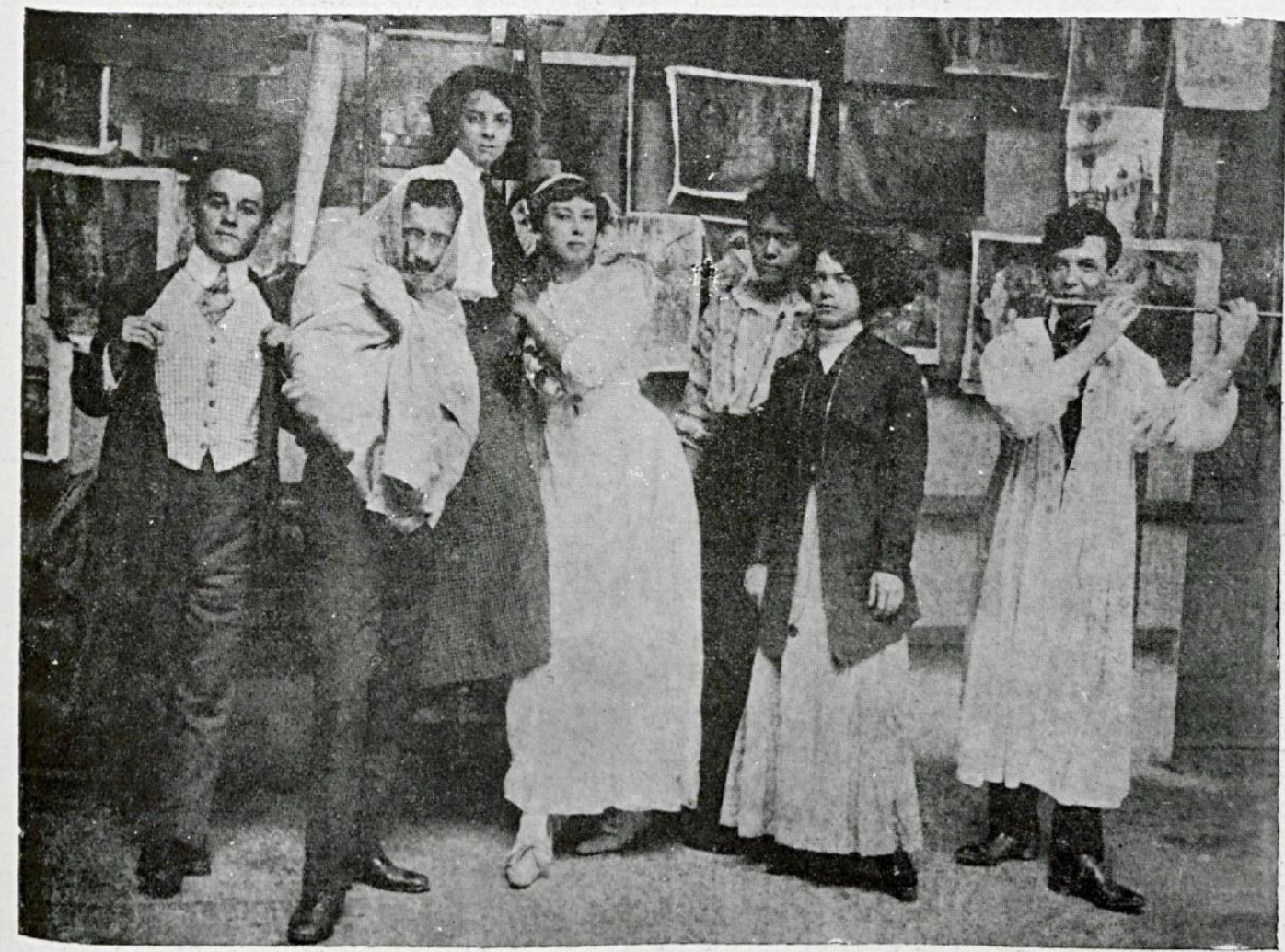

Grupo de discipulos do professor Elyseo Viscont

(da esquerda para a direita) Galdino Bicho, Marques Junior, Isolina Machado, Silvia Meyer, Adelaide Gonçalves, Fedora Rego Monteiro e H. Cavallero.

Fonte: Fon-Fon!, ano IV, n. 42, p. 3. Rio de Janeiro, 15 out. 1910.

Algo semelhante aparece nas inúmeras imagens de senhoritas que ingressavam nas escolas superiores, retratadas pelas revistas sob o rótulo de "Nosso Feminismo". Essas imagens mostram que, nas cerimônias de formatura, as moças usavam um traje unissex fraque, camisa de colarinho alto e gravata borboleta, associados a cabelos curtos - que, do ponto de vista do gênero, ressalta uma aparente igualdade entre os sexos. Num dos textos 
que acompanham as imagens, o cronista ressalta que, pelas 8 e 9 da noite, via as jovens estudantes passando nos bonds da Lapa, de volta do Pedagogium, ou circulando pelo Largo de São Francisco, carregadas de rolos de papel. Imagens e textos confirmam, assim, não só a movimentação, em locais públicos, de jovens mulheres lançadas à conquista de educação e espaços sociais no início do século XX, como também associam essas conquistas aos trajes alternativos à moda feminina burguesa.

Mirtes de Campos foi a primeira mulher a entrar na Escola de Direito do então Distrito Federal, ainda na década de 1880. Em 1910, já era Diretora do Departamento Nacional de Ensino e considerada uma grande criminalista. ${ }^{26} \mathrm{~A}$ advogada era regularmente fotografada pelas revistas ilustradas, caminhando pela Avenida Central como uma dama trajada na moda elegante da belle-époque. Saias tulipa, com cós alto, chemisette bordada em renda conforme descrição dos editoriais de moda da época -, com colarinho alto e dobrado e chapéu volumoso arrematado por um grande laço de fita. Mirtes tinha uma trajetória profissional que afrontava os ideais de feminilidade da época: advogava em defesa da mulher e das classes trabalhadoras, declarava-se a favor do divórcio e era, acima de tudo, uma feminista atuante. Mas ao vestir-se como uma elegante dama burguesa, ela parecia dar continuidade à tática das sufragistas inglesas que se vestiam na última moda de Paris para afirmarem sua feminilidade, numa época em que as feministas eram consideradas mulheres-homens. Contudo, um elemento destoava na indumentária feminina burguesa elegante de Mirtes, sinalizando sua identidade como profissional: ela sempre carregava rolos de papel, como em geral faziam as mulheres que trabalhavam fora, em profissões que exigiam acesso à educação. Por sua trajetória feminista, Mirtes não escapou aos detratores. Enquanto as fotografias a mostram como uma dama elegante e feminina, em espaço reservado às personalidades do grand monde carioca, o caricaturista Klixto, por exemplo, a apresentava em seus desenhos com traços masculinizados. Na visão de Klixto, Mirtes era, por sua atuação profissional, uma paladina do feminismo - ou seja, uma mulher-homem.

Em 1910 foi criado no Brasil o Partido Republicano Feminino (PRF). Suas fundadoras foram a professora primária e primeira sertanista brasileira Leolinda Daltro, ${ }^{27}$ a poetisa Gilka Machado, descrita por um contemporâneo como uma "mulatinha clara"; e a então primeira dama, Orsina da Fonseca. O partido, que tinha como mentoras mulheres intelectualizadas, arregimentava também um grande número de professoras primárias, as quais viam como necessidade premente a organização de um partido a favor do voto feminino, considerado por elas a única possibilidade de combater a discriminação contra as mulheres e possibilitar sua entrada no mercado de trabalho.

Uma fotografia (Figura 3) publicada na Revista de Semana, em setembro de 1911, sobre uma passeata promovida pelo PRF no Catete, mostra jovens militantes do partido.

\footnotetext{
26 GUIMARÃES, Lucia Maria Paschoal; FERREIRA, Tania Maria Bessone de Cruz. Myrthes Gomes de Campos (1875-?): pioneirismo na luta pelo exercício da advocacia e defesa da emancipação feminina. Gênero, Niterói (RJ), v. 9, n. 2, 135-151, 2009.

${ }^{27}$ CORREA, Mariza. Os Índios do Brasil Elegante \& a Professora Leolinda Daltro. Revista Brasileira de História, São Paulo, v. 9, n. 8, 43-65, ago./set. 1989.
} 
Segundo o jornal O Paiz, na edição de 21 de outubro de 1911, as militantes do PRF se reuniam em passeatas e outros atos públicos portando distintivos que as identificavam como grupo: roupas brancas, faixas, insígnias e a bandeira do partido. O jornal informa ainda que uma tática política do PRF era marcar presença na Câmara, no Senado e em todas as comemorações cívicas. Mas a observação da Figura 3 suscita algumas questões: quais seriam as razões para um grupo de mulheres militantes feministas racialmente mestiças e provenientes das classes médias e baixas assumirem como auto-imagem a indumentária feminina burguesa? E por que elegeriam o branco como cor de identificação do grupo?

\section{Figura 3}

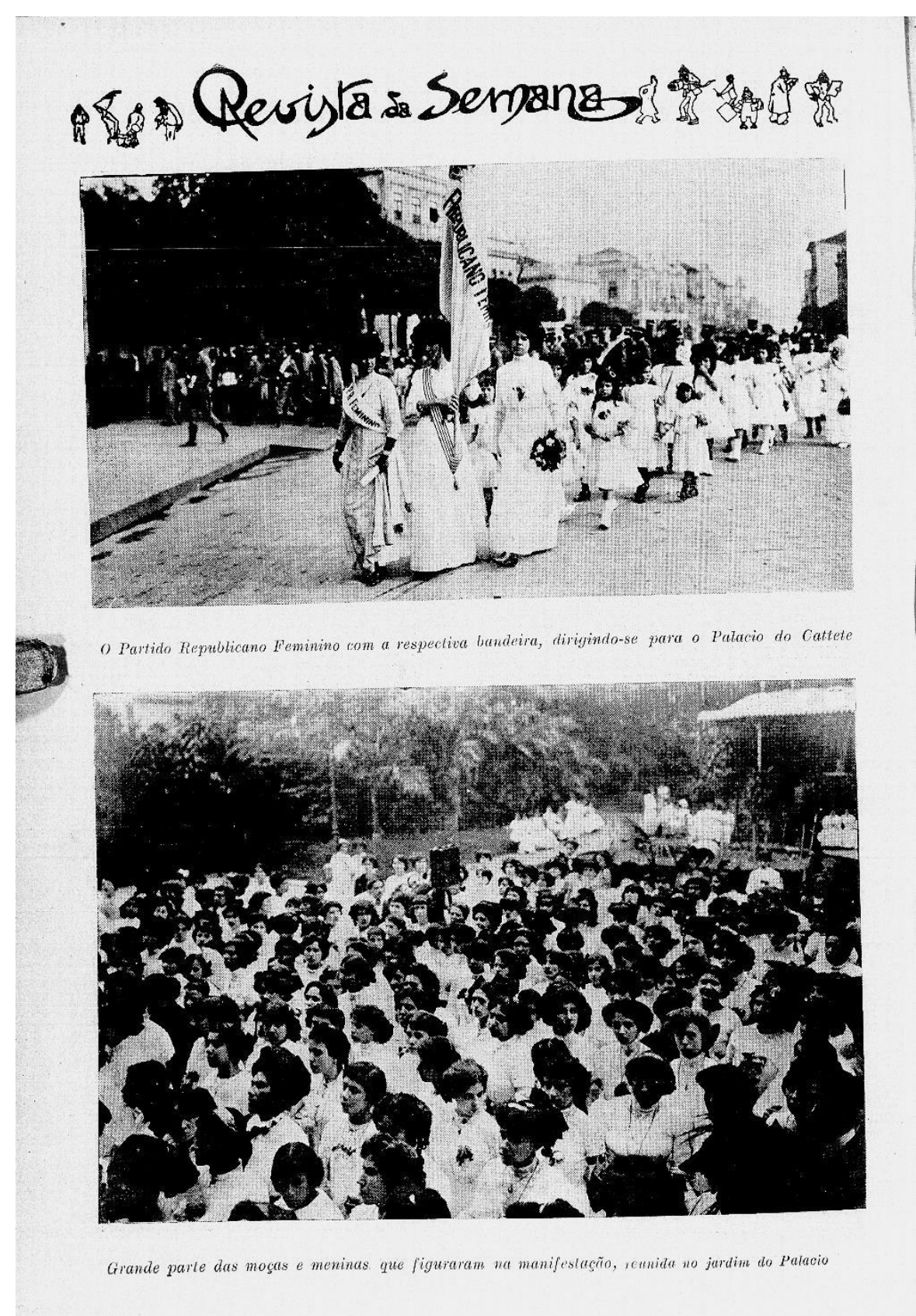

Fonte: Revista da Semana, ano XII, n. 594, p. 10. Rio de Janeiro, 30 set. 1911. 
Sabemos que, no final do século XIX, a cor branca tinha se tornado símbolo das sufragistas inglesas em sua campanha pelo voto feminino. Portanto, uma das explicações possíveis para a adoção do branco pelas brasileiras militantes do PRF seria uma alusão à campanha das sufragistas inglesas. Por outro lado, essas mulheres militantes sabiam que eram julgadas não apenas por suas atitudes, como também por sua aparência. Assim, a resposta às duas questões acima pode estar numa decisão de vestirem roupas elegantes, de acordo com os padrões da moda burguesa das classes altas, para mostrar que não eram mulheres masculinizadas; e de usar a cor branca para aludir à pureza feminina na vida privada e pública, tornando-a também um dispositivo identificador dos propósitos da luta. Nesse caso, podemos ler a aparência e a roupa das militantes do PRF não como um sinal de conformidade com os padrões femininos burgueses, mas como uma estratégia deliberada - portanto, como um mecanismo político para desafiar as definições de feminilidade e cidadania da época.

Aprofundando um pouco mais nossa reflexão sobre a indumentária das jovens militantes, percebemos que esta pode sinalizar, também, uma intervenção política feminina no universo masculino, através da utilização de uma aparência essencialmente feminina. De modo que, ler a aparência dessas mulheres como convencionalmente feminina e, portanto, concluir que, em alguma medida, elas estavam em desacordo com as intenções de sua ação política, talvez seja perder o fio da meada. A relação da mulher com sua aparência pode ser lida na chave dos questionamentos de Simone de Beauvoir, em O Segundo Sexo, onde a autora pergunta-se "o que é ser mulher" e ela mesma responde: "Não se nasce, mas se faz mulher". ${ }^{28}$ Ser mulher, no contexto em questão, é tornar-se atuante na esfera pública e, portanto, recusar a limitação à esfera exclusivamente privada, agindo livremente em domínios exclusivamente masculinos, como a rua. Nesse caso a mulher não está na rua para se exibir ao olhar masculino, mas para exigir seus direitos e espaços sociais como sujeitos em uma estratégia político performática.

De modo que, se a passeata, como espetáculo performático feminino, combinava modos de vestir com comportamentos sociais, por um grupo social feminino não exclusivamente burguês, o ato pode nos revelar uma possibilidade de subversão através de uma dramatização pública. A roupa usada por elas, aparentemente em conformidade com os padrões femininos burgueses da época, ocupa na dramatização outra função: a de estratégia política - como protesto e/ou como demonstração de uma consciência política explícita, que se deixa ver através de uma identidade partilhada pelo vestir. Judith Butler afirma que as identidades são construídas na repetição de atos. ${ }^{29}$ Sendo assim, a roupa e os corpos em ato performático são mecanismos políticos performáticos que desafiam as definições de identidade feminina e de cidadania da época.

A mesma estratégia das militantes do PRF era adotada por comerciárias e datilógrafas em disputa por postos de trabalho com os homens. As datilógrafas, por sinal, foram as profissionais que mais afrontaram os homens, à época. Num anúncio publicitário da escola de

\footnotetext{
${ }^{28}$ BEAUVOIR, Simone. O Segundo Sexo: Fatos e Mitos. São Paulo: Difusão Europeia do Livro, 1970, p. 9.

${ }^{29}$ BUTLER, Judith. Problemas de Gênero... Op. cit., p. 76.
} 
datilografia Remington publicado na edição de Fon-Fon! de maio de 1910 (Figura 4), vemos uma datilógrafa vestindo saia e camisa risca de giz (peça de alfaiataria típica pelo corte, modelagem e tecido usados especialmente na confecção de roupa masculina), acompanhada de gravata. Em seu processo de inserção no mercado de trabalho, as datilógrafas disputavam empregos com os homens e frequentemente os desbancavam. Candidatos homens perdedores enviavam missivas de protesto aos jornais. Em 1911, um candidato argumentava em carta para o jornal $A$ Noite: "só poderão se inscrever nos concursos de datilografia cidadãos brasileiros e só é cidadão toda pessoa que está no gozo de seus direitos civis e políticos, logo quem não tem direito de voto não é cidadão". Mas as datilógrafas eram vistas pela imprensa em geral como excelentes trabalhadoras. É verdade que seus salários eram muito inferiores aos dos homens, os postos ofereciam pouca ou nenhuma oportunidade de ascensão profissional e, acima de tudo, as mulheres constituíam uma força de trabalho fácil de dirigir sob a supervisão masculina. ${ }^{30}$ Contudo, o importante para nossa análise aqui é o fato de que as mulheres das classes médias conquistaram espaço de trabalho em escritórios, o que lhes possibilitou mais liberdade econômica e comportamental, incluindo-se aí o uso de indumentária indicativa de independência.

Figura 4

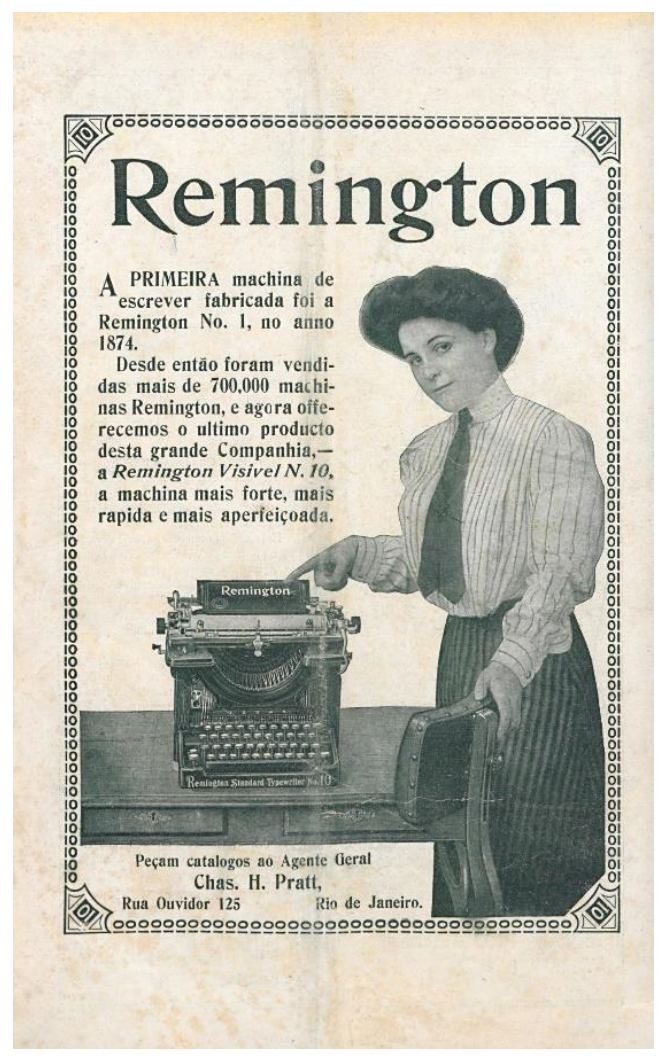

Fonte: Fon-Fon!, ano IV, n. 5, p. 36. Rio de Janeiro, 29 jan. 1910.

\footnotetext{
${ }^{30}$ HAHNER, June E. A Mulher Brasileira e... Op. cit. , p. 87.
} 


\section{Conclusão}

O caricaturista Raul Pederneiras, um ferrenho antifeminista e opositor de qualquer atuação profissional da mulher, registra em caricatura na capa da revista Fon-Fon! (Figura 5) as sufragistas do PRF em campanha pelo voto feminino, em 1914. A imagem ilustra os argumentos expostos acima. Vemos que o caricaturista se utiliza de vestuário, classe social, idade e raça como marcadores visuais da nova classe de mulheres. Percebemos na imagem que a moda, além de funcionar como código de distinção nas construções de gênero, identifica estilos de vestir com estilos de comportamento feminino.

\section{Figura 5}

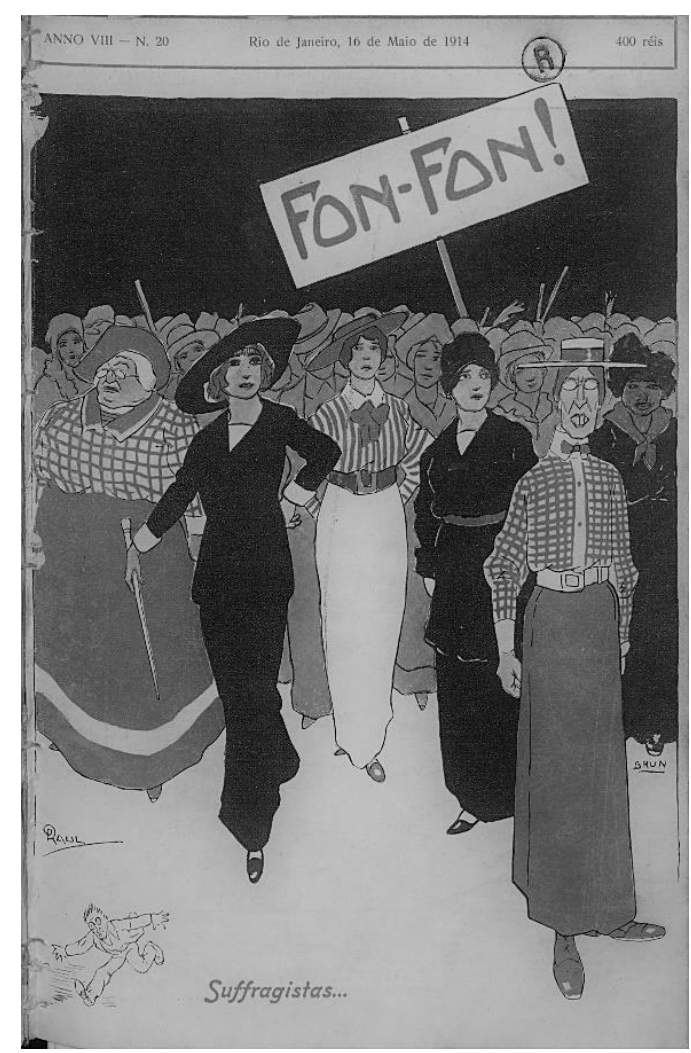

Fonte: Fon-Fon!, ano VIII, n. 20, capa. Rio de Janeiro, 16 maio 1914.

No primeiro plano, Pederneiras apresenta um grupo de mulheres que inclui matronas e jovens militantes, sendo uma delas negra. No segundo plano, vê-se um conjunto de mulheres munidas de paus. As que estão no primeiro plano se vestem no estilo alternativo ao burguês feminino. Como tal estilo alternativo aparece associado no desenho à mistura de classe e de raça, a imagem inevitavelmente chama atenção para a diversidade social de mulheres integrantes dos novos grupos femininos que passaram a frequentar o espaço urbano; incluídas 
nesses grupos, estão as temíveis feministas que, com seus pedaços de pau, atemorizam o caricaturista, como podemos ver ao lado esquerdo, na parte inferior da imagem.

Dessa forma, Pederneiras revela em seu desenho que os novos grupos de mulheres que adentraram o espaço público em busca de educação e trabalho eram social e racialmente heterogêneos. Mostra também que o estilo de vestir adotado por esses grupos funcionou como afirmação de uma nova identidade feminina, transformando-se em ferramenta política das mulheres em seu esforço de avançar na hierarquia social. Essas constatações nos levam a concluir que a luta entre homens e mulheres no início do século XX expressou não apenas uma batalha entre os sexos, mas um conflito de gênero, de classe e de raça; e que, ao associar novos modos de vestir a novos comportamentos sociais, a indumentária adotada pelas mulheres estudantes ou trabalhadoras funcionou como dispositivo político em sua luta por emancipação. 